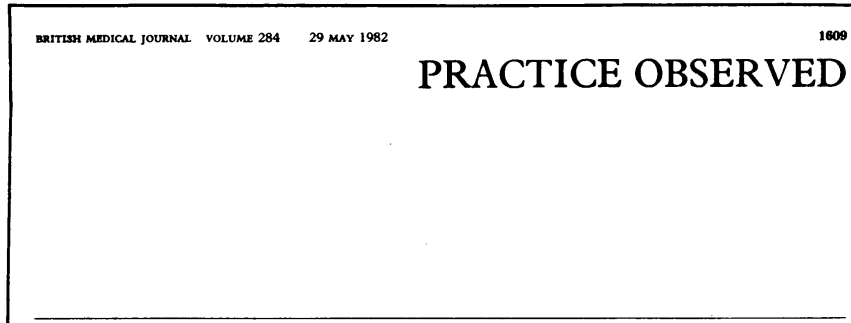

\section{The GP and the Specialist}

\section{ENT}

HAROLD LUDMAN

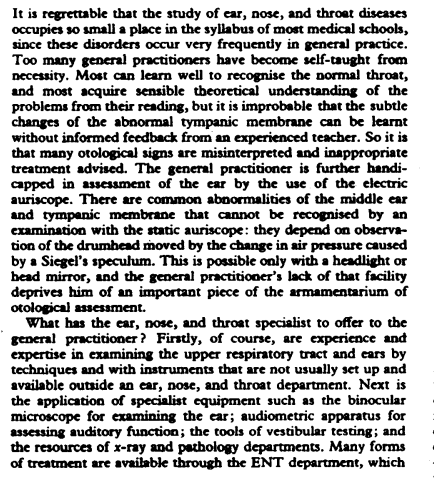

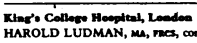

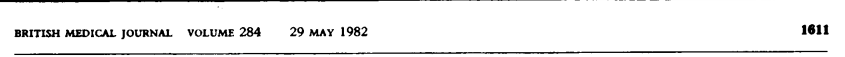

Practising Prevention

\title{
Pregnancy
}

M J V BULL

The dims of moderm matemity care arc the carly diegrosis of
variations from the norm and detection of

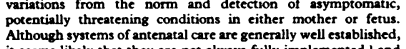

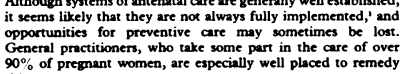

Preconcepptual cere

No woman need conceive before she intends to do so. It
has been shown that premature pregnancy (especially in teenage

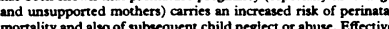

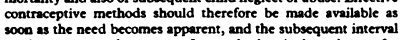

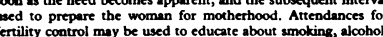

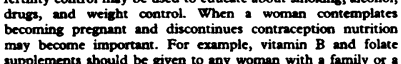

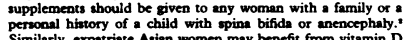

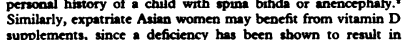

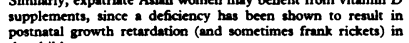

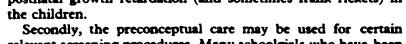

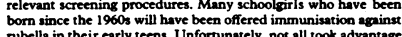

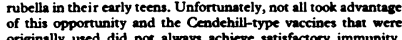

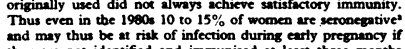

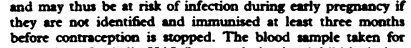

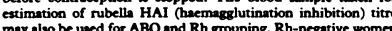

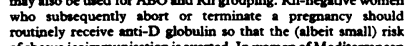

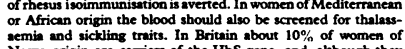

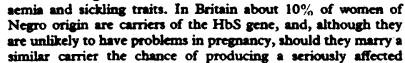

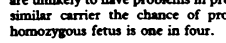

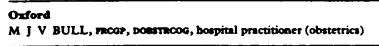

Finally, adrantage should be ceaken during this preconoceptual

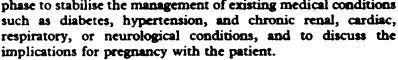

Antenatal care

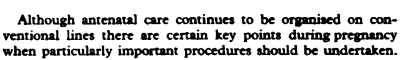
piest consurtation

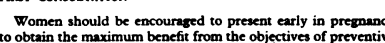

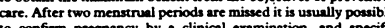

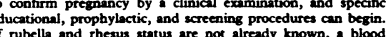

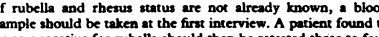

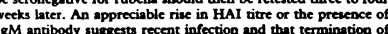

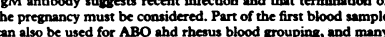

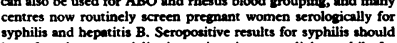

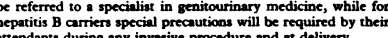

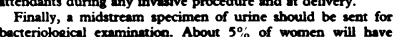

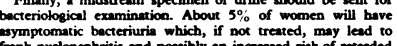

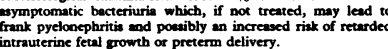

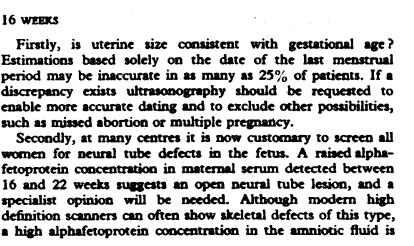

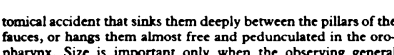

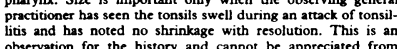

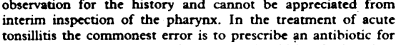

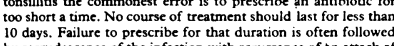

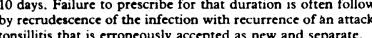

Secretory odtits media and the "glue ear"

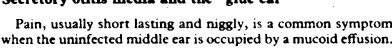

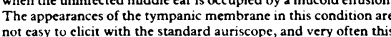

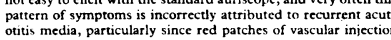

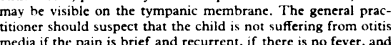

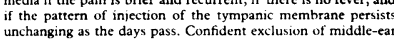

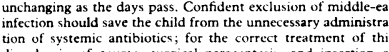

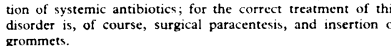

Nasal disorders

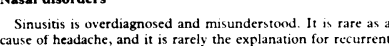

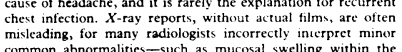

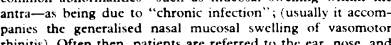

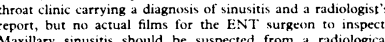
Maxiliary sinusitis should be suspected frem a radiological
examination only when an antrum is opaque or contains a flui

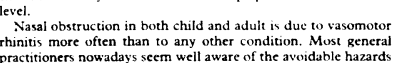

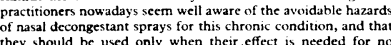

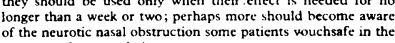

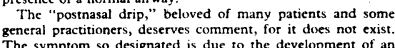

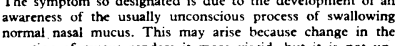

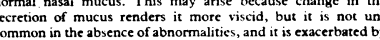

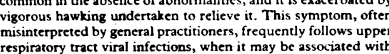

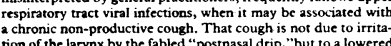

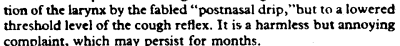

BRTISH MEDICAL JOURNAL VOLUME $284 \quad 29$ MAY 1982 Vertigo The two commonest errors are probably the failure to recog-
nise benign paroxysmal positional vertiog, and overdiagnosisMenizer's disease, particularty in elderly patients. Benign
paroxysmal positional vertigo is so casily recognised by performing a positional test and watching the characteristic rotatory
nystagmus, accompanied by vertigo, developing after a atent period, and fatizuing within seconds, that it should easily be
diagnosed in the home. Meniere's disease is never an accurate

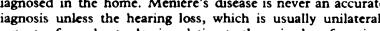
huctuates from day to day in relation to the episodes of vertigo.
and is accompanied by intolerance for loud sounds, and whe and is accompanied by intolerance for loud sounds, and whe
other causes of endolympharic hydrops have successfully been excluded. Too often tinnitus due to presbycusis (hearing Chronic ear disea

The treatment of chronic middle-ear infection with dis-
charge rarely calls for the use of systemic antibiotics. Whether it is safe tubotympanic disease, or the nastier cholesteatomato
variety, the discharge will not respond to systemic drues since Gram-negative rods insensitive to any antibiotic safte for
systemin administration. Treatment is first by aurat rovilet nudder
illumination, with the instillation of local antibiotics, often combined with steroids. The exception would be when an e
with a perforated drum has an acute infection, recognisable by with a perforated drum has an acute infectuon, recognisable by Otalgia

Pain in the ear is often inadvisably treated with antibiotiots
even when there is no firm evidence of middle-ear diccasc. Th
pain is offen referred - from the wisdom teeth, jaw joints, upp cervical spine, or crevices of the upper food passageway,
Referred pain should always be suspected if the tympanic
membrane on the affected side is truly nermal. This absuse of membranc on the affected side is truly normal. This abuse of
antibiotics probably bespeaks lack of confidence on the part of
the general practititinere in recognising normality,

Datares

In managing deafness, particularly of recent onset, criticism
can be levelled at the excessive reliance on syringing. Too often it seems to he cused as a diagnostic test, probably because manty bour their symptom but for a "syringe." Sudden deafness olerated by the patient and the general practitioner-in circum-
tances that would not obtain with sudden loss of sight in on eye. Urgent referral for specialist advice must be advocated.
Temporary or intermittrent deafness is too offera ascribed by whe egeneral practitioner to Eustachian tube troubles and treated
with decongestants. The high prevalence of cochlear hydrop
with flucturing hearing loss in the inner ear, is not suficienty with fluctuation
appreciated.

The throat

Diseases of the throat have, fortunately, been well advertised and it is now unusual for a general practitioner to delay referra
of patients with haorseness lasting for more than the statutory
1812

also evidence of an open lesion and an indication for mid-
trimester abortion. Amniocentesis should also be offered to any women with a
history of previous chromosomal or neural tube defect or a
family history of In women aged 37 years and over the probabilitiry of the fetus
having Down's syndrome becomes greater than the risk to the request he procedure.
Thirdly any with a history of miderimester abortion
(either spontaneous or induced) or previous carly preterm (either spontancous or inducted a
delivery should have a careful vaginal examination. Effacement, laceration, or appreciable dilatation of the cervix at this stage
may be an indication for cervical cerclage, although the true has yet to be critically evaleated. Finally, 16 weeks of gestation is the appropriate time for the
patient to receive iron and folate supplements to guard against patient to receive iron and folate supplements to guard against
subsequent develomento of iron deficiency or marcocycic
anaemias of pregancy. The necessity for these supplements in 28 weEks

Examination at 28 weeks is of particular impotance since forms a aseline to which deviations from the norm in the third
trimester may be related A A bood sample should be checked
for sat for anacmia and, in rhesus-negative women, for the presence of
rhesus antibodics. The gestational age of the fetus should be carcfully reassessed on clinical evidence and, if necessary, by
ultrasound measurement. Poor maternal weight gain associated ultrasound measurement. Poor maternal weight gain associated
with poor uterine growth arce important predictions of fetal
grow ments and maternal urinary oestrogen assays (as indicators of
placental function') may be advisatle. Women with a history of pre-eclampsia are at risk of both recturrence of this condition and
of fetal growth retardation, and .raised plassma urate concen-
tantions at 28 wecks may predict this. Any history of bleeding trations at 28 weeks may predict this. Any history of bleeding
in the second trimester is sinister, suggesting placental mal-

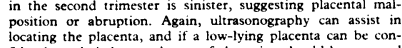
fidently excluded some degree of abruption should be assumed
and specialist opinion sounht. 34 TO 36 wEEKS

Maternal bloxd must again be screened for anaemia and
rhesus or other antibodies. Fetal growth should be formally reassessed and investigations starred if there is a suspicion of
growht retardatation. Dynamic tests of fetal wellibeing may now
alsw be also be appropriate. The simplest is the subectuve ietal kick
chart, which is completed daily by the mother and should be reviewed at weckly inervals Fxiernal cardioncography may also be advisable; if the fetal heart rate does not respond to fetal
movement this suggests poor placental function and thus a fetus Malpresentation should be obvious by this stage of pregnancy.
If a brech or transverse lie is found the advisability of external version must bc considered. In nulliparae, if version is contraindicated or not feasible, a careful clinical and radoloogical
assessment of the pelvis should be made. Any paticnt whose
pelvic architecture is less than optimal may better be delivered when the presentation is cephalic, cephalopelvic disproposon need rarely be considered before the paticnt is in labour."
Finally, infective agents sin the birth canal may threaten the
inter infant during parturition. In any woman with a past history of
herpes genitalis a high vaginal swab should be taken and sent herpes genitalis, a high vaginal swab should be taken and sent
in transport medium for virologicat examination. If herpes virus

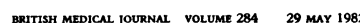
than vaginally. Similarly, since perhaps one in eight women are
asymptromatic vaginal carriers of group $\mathrm{B}$ Bstreptococcusus, and the there may be a case for investigating all patients bacteriological

ONE WEER PAST TERM

Perinatal mortality increases with the duration of post-
maturity. Evidence regarding accuracy of gestational dorting should be reviewed in any woman who is still undelivered one week past term. If no reasonable doubts exists regarding her Conclusion

The main causes of perinatal morality and morbidity toda are preterm delivery, congenital defect, and intrauterine hypoxia
Although little progress has been made in either predicting oo averting the preterm delivery, genetic congenital anomalies can
now often be detected and the fetus aborted. Other defects - for example the results of rubella infection in early pregnancy-
could, with a sufficiently enthusiastic programme for prophylaxi be entirely eliminated. Intrauterine hypoxia, presenting as fetal
grouth retardation, is all too often overlooked but the outcom
in terms of feral wastage could be grealy improved if a higher in terms of feral wastage could be greatly yimproved if a higher
index of suspicion existed and appropriate management was mplemented. General practitioners, in fulfflling their role in the care of women in their ferrile years, are in a strong position to
initiate the appropriate programmes for prevention and so make

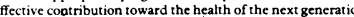

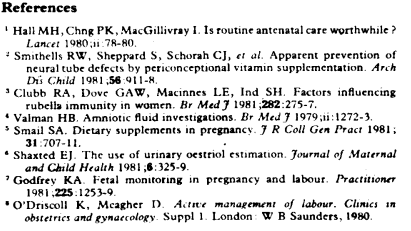

ONE HUNDRED YEARS AGO Dr RA Jamicson of Shanghai a pair of feet, to which the following remarkable history is atrached.
Some months ago, a Chiness begarar excited much piry, and madc

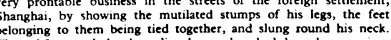
Warned frequently by the policec, he was knocked down by a carriage
ace day when scrambling out of the way of a constable. He wan

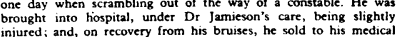

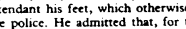
政

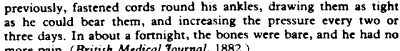

